\title{
EVALUASI DAKTALITAS STRUKTUR BETON BERTULANG AKIBAT PENGARUH DINDING PENGISI BATA MERAH
}

\author{
Mizanuddin Sitompul \\ Dosen Pengajar Program Studi Teknik Sipil, Fakultas Teknik, UMSU, Medan \\ Surel : mizanuddins@gmail.com \\ Diterima : 13 Oktober 2017; Disetujui : 20 Oktober 2017
}

\begin{abstract}
ABSTRAK
Dinding pengisi bata merah sangat jarang diperhitungkan keberadaannya dalam perencanaan suatu struktur beton bertulang. Hal ini mengakibatkan pengaruh kekuatan dan kekakuan dinding pengisi tidak diperhitungkan dalam perencanaan suatu bangunan. Sering sekali dalam perencanaan bangunan diasumsikan sebagai struktur open frame dengan dinding bata non struktural hanya sebagai beban gravitasi yang bekerja pada balok. Padahal pada berbagai kasus gedung dengan pengaruh gempa, ternyata dinding bata ikut memikul beban lateral. Hal ini dapat dilihat dengan terjadinya pola retakan pada dinding bata yang menunjukkan terjadi transfer beban dari portal ke dinding bata. Penelitian ini bertujuan untuk mengetahui seberapa besar perubahan daktilitas struktur akibat pengaruh dinding bata merah
\end{abstract}

Kata Kunci : daktilitas, dinding pengisi, equivalent diagonal strut, analisis pushover, performance point

\begin{abstract}
The clay brick infill panels are seldom included in design analysis of reinforced concrete structural systems. So that it influences the strength and stiffness of the infill panels not considered in planning building construction. Usually, in designing, the structural system is assumed as an open frame structure with non structural clay brick panels considered as gravity loads on the beam. In facts, in many earthquake cases, the panels participates in carry on the lateral load. The crack pattern on panels show that the load transfering from frame to panels. The aim of this study was to find out the influence of the clay brick panels on structure ductility.
\end{abstract}

Keywords: clay brick infill panel, ductility, equivalent diagonal strut, performance point, pushover analysis

\section{Pendahuluan}

Bata merah merupakan salah satu material yang sering digunakan sebagai dinding pengisi pada bangunan di Indonesia, terutama sebagai penutup luar ataupun partisi pemisah di bagian dalam untuk kebutuhan arsitektural maupun kepentingan estetika bangunan khususnya untuk bangunan rendah dan bertingkat sedang. Hal ini dikarenakan bata merah memiliki nilai estetika, sifat harga yang ekonomis, mudah didapat, dan tahan terhadap cuaca.

Dinding bata tersusun oleh material batu bata dan mortar yang memiliki nilai kekuatan dan kekakuan tertentu. Di Indonesia pada umumnya dinding pengisi hanya diperhitungkan sebagai beban yang disalurkan ke struktur sehingga mengakibatkan pengaruh kekuatan dan kekakuan dinding pengisi tidak diperhitungkan dalam perencanaan suatu bangunan. Dinding pengisi ini akan memberikan sumbangan kekakuan yang cukup berarti pada struktur terutama saat menahan gaya lateral seperti gempa. Biasanya dalam perencanaan, bangunan diasumsikan sebagai struktur open frame dengan dinding bata non struktural hanya sebagai beban gravitasi yang bekerja pada balok.

Dalam beberapa kasus gempa, ternyata dinding bata ikut memikul beban lateral. Keretakan yang terjadi pada dinding bata menunjukkan terjadi transfer beban dari portal ke dinding bata. Selain itu, pada beberapa bangunan terjadi mekanisme keruntuhan softstory. Keruntuhan soft-story diakibatkan karena konfigurasi dinding pengisi yang berbeda antara lantai satu dengan lantai-lantai di atasnya. Kekuatan dan kekakuan dinding bata 
ini tidak bisa diabaikan begitu saja. Tulisan ini bertujuan untuk mengetahui seberapa besar perubahan daktilitas struktur akibat pengaruh dinding bata merah.

\section{Kajian Pustaka}

\subsection{Dinding Pengisi}

Dinding pengisi yang digunakan dalam penelitian ini adalah dinding batu bata merah, karena sangat banyak digunakan hampir di seluruh bangunan-bangunan pada wilayah negara Indonesia. Bata merah (clay brick) adalah bahan bangunan yang digunakan untuk pembuatan konstruksi bangunan, dibuat dari tanah liat dengan atau tanpa campuran bahanbahan lainnya yang dibentuk persegi panjang, dibakar pada suhu yang tinggi hingga tidak dapat hancur lagi bila direndam dalam air.

Perilaku portal dengan dinding bata terhadap pembebanan lateral telah lama diselidiki, misalnya oleh Holmes (1961), Smith (1966), Dawe dan Sheah (1989), Mehrabi dkk. (1996), Mehrabi dan Shing (1997), Madan dkk. (1997) dan lain-lain. Dari beberapa penelitian yang ada, pemodelan dinding bata sebagai bracing tekan yang diteliti oleh Saneinejad dan Hobbs (1995) dinilai paling sederhana namun representatif. Metode ini telah memperhitungkan perilaku elastis dan plastis portal isi dengan mempertimbangkan adanya daktilitas yang terbatas dari material dinding pengisi. Metode ini lebih dikenal dengan nama metode Equivalent Diagonal Strut.

\subsection{Diagonal Tekan Ekivalen (Equivalent Diagonal Strut) SANEINEJADHOBBS}

Portal-Isi dianggap sebagai portal tidak bergoyang (braced framed), dimana dinding pengisi akan berfungsi sebagai diagonal tekan ekivalen (equivalent diagonal strut). Diagonal tekan ekivalen hanya kuat terhadap gaya tekan saja. Pengaruh beban lateral bolak-balik akibat gempa dapat diatasi dengan terbentuknya diagonal tekan pada arah lain yang juga mengalami tekan (lihat Gambar 1).

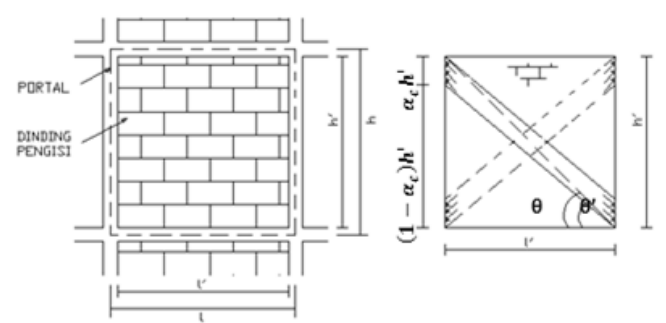

Gambar 1. a) Portal isi; b) Penopang diagonal bolakbalik (Saneinejad dan Hobbs, 1995).

\subsection{Diagonal Tekan Ekivalen (Equivalent Diagonal Strut) FEMA 273}

Lebar efektif diagonal compression strut yang digunakan untuk menganalisis kekuatan dan kekakuan dinding pengisi bata berdasarkan model FEMA 273 dihitung dengan menggunakan Pers. 1 dan Pers. 2.

$$
\begin{gathered}
a=0,175\left(\lambda_{1} h_{c o l}\right)^{-0,4} r_{\text {inf }} \\
\lambda_{1}=\left[\frac{E_{m e} t_{\text {inf }} \sin 2 \theta}{4 E_{f e} I_{\text {col }} h_{\text {inf }}}\right]^{\frac{1}{4}}
\end{gathered}
$$

dimana $\mathrm{h}_{\text {col }}=$ tinggi kolom di antara as-balok, $\mathrm{h}_{\text {inf }}=$ tinggi dinding pengisi, $\mathrm{E}_{\mathrm{fe}}=$ modulus elastisitas material portal, $\mathrm{E}_{\mathrm{me}}=$ modulus elastisitas material dinding pengisi, $\mathrm{I}_{\mathrm{col}}=$ inersia penampang kolom, $\mathrm{L}_{\mathrm{inf}}=$ panjangdinding pengisi, $r_{\text {inf }}=$ panjang diagonal dinding pengisi, $\mathrm{t}_{\text {inf }}=$ tebal dinding pengisi, $\theta=$ sudut yang dibentuk antara tinggi dan panjang dinding pengisi, $\lambda_{1}=$ koefisien yang digunakan untuk menentukan lebar efektif strut, a= lebar efektif strut.

\section{Metodologi}

Struktur dimodelkan terdiri dari 6 lantai dan 3 bentang (Gambar 2). Tinggi untuk lantai pertama adalah $4 \mathrm{~m}$, sedangkan untuk lantailantai lainnya $3,5 \mathrm{~m}$. Masing-masing model mempunyai panjang bentang $5 \mathrm{~m}$ kecuali di bagian tengahnya $3 \mathrm{~m}$. Perletakan diasumsikan jepit. Struktur diasumsikan terletak di atas tanah sedang dan berada di zona gempa kuat. Peruntukan bangunan diasumsikan sebagai perkantoran. Untuk preliminary design ditetapkan dimensi balok $40 \times 60 \mathrm{~cm}$, kolom 60 x $60 \mathrm{~cm}$, dan tebal plat lantai/atap $12 \mathrm{~cm}$.
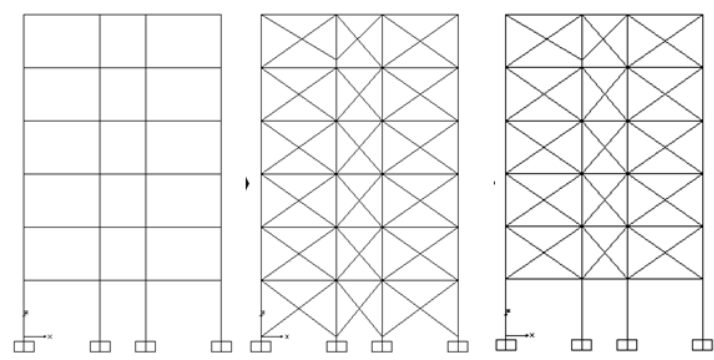

Gambar 2. Pemodelan struktur (a) open frame (model 1); (b) fully-infilled wall frame (model 2); (c) open first-story frame (model 3).

Pada studi ini digunakan bata merah sebagai material dinding pengisi. Karakterisitik dinding bata yang akan digunakan didasarkan 
Evaluasi Daktalitas Struktur Beton Bertulang Akibat Pengaruh Dinding Pengisi Bata Merah

pada karakteristik dinding bata hasil pengujian laboratorium yang dilakukan oleh Aryanto (2008) dimana kuat tekan unit bata 4,57 Mpa, kuat tekan rata-rata pasangan bata (fm') 3,54 Mpa, modulus elastisitas dinding pengisi 2478 Mpa, kuat Lekat/ bond pasangan bata 0,39 Mpa, dan regangan pada tegangan maksimum, $\varepsilon_{\mathrm{c}}=$ 0,002 .

Elemen balok dan kolom dimodelkan sebagai balok Giberson (lumped plasticity model) untuk pemodelan elemen nonlinier. Kondisi tidak linier tidak elastis pada sendi plastis diwakili oleh parameter-parameter momenrotasi untuk balok dan kolom. Elemen dinding pengisi dimodelkan menjadi sebuah elemen garis yang memiliki kekuatan dan simpangan yang getas (brittle). Untuk mendapatkan parameter ini digunakan persamaan yang diajukan oleh Saneinejad-Hobbs (1995). Elemen garis (strut) ini hanya menerima gaya tekan akibat beban lateral.

Properti material nonlinier pada studi ini seperti kapasitas rotasi pasca leleh (rotasi plastis), $\theta_{p}=0,06$; kapasitas rotasi pasca kondisi plastis $\theta_{\mathrm{pc}}=0,06$ dan rotasi leleh $\theta_{\mathrm{y}}$ dihitung dengan $\theta_{\mathrm{y}}=\mathrm{My} / \mathrm{K}_{0}$. Nilai rasio antara momen maksimum dengan momen leleh adalah $\mathrm{M}_{\mathrm{c}} / \mathrm{M}_{\mathrm{y}}$ $=1,19$. Kekakuan elemen dihitung dengan $\mathrm{K}_{0}=$ 6EI/L. Momen inersia efektif diasumsikan $40 \%$ dari momen inersia biasa $\mathrm{I}_{\mathrm{ef}}=0,4 \mathrm{I}$.

Analisis pushover dilakukan untuk melihat seberapa besar daktilitas dari struktur yang ditinjau. Tipe analisis pushover yang digunakan dalam studi ini adalah kontrol displacement dimana struktur didorong sampai mencapai displacement yang diinginkan dan atau sampai struktur yang ditinjau runtuh. Efek P-Delta diabaikan. Untuk mendapatkan titik kinerja (performance point) pada studi ini digunakan Capacity Spectrum Method atau Metoda Spektrum Kapasitas (ATC-40).

\section{Hasil dan Pembahasan}

Perbandingan titik kinerja dan daktilitas untuk berbagai model dapat dilihat pada Tabel 1, persentase peningkatan dan penurunannya pada Tabel 2, dan perbandingan kurva kapasitas tiap model pada Gambar 3.

Tabel 1: Perbandingan titik kinerja (performance point) dan daktilitas dari model struktur.

\begin{tabular}{lccc}
\hline $\begin{array}{c}\text { Model } \\
\text { Struktur }\end{array}$ & $\begin{array}{c}\text { Gaya } \\
\text { Geser } \\
\text { dasar } \\
\text { (kN) }\end{array}$ & $\begin{array}{c}\text { Perpind } \\
\text { ahan } \\
\text { (m) }\end{array}$ & $\begin{array}{c}\text { Dakti } \\
\text { litas }\end{array}$ \\
\hline $\begin{array}{l}\text { Open Frame } \\
\text { (Model 1) }\end{array}$ & 472,040 & 0,030 & 11,89 \\
\hline $\begin{array}{l}\text { Fully Infilled } \\
\text { Wall Frame } \\
\text { (Model 2) }\end{array}$ & 502,223 & 0,029 & 9 \\
\hline $\begin{array}{l}\text { Open First- } \\
\text { Story Frame } \\
\text { (Model 3) }\end{array}$ & 476,285 & 0,028 & 10,38 \\
\hline
\end{tabular}

Tabel 2: Perbandingan titik kinerja (performance point) dan daktilitas dari model struktur.

\begin{tabular}{ccc}
\hline $\begin{array}{c}\text { Model } \\
\text { struktur }\end{array}$ & $\begin{array}{c}\text { Peningkatan } \\
\text { gaya geser } \\
\text { dasar (\%) }\end{array}$ & $\begin{array}{c}\text { Penurunan } \\
\text { daktilitas } \\
(\%)\end{array}$ \\
$\begin{array}{c}\text { Fully Infilled } \\
\text { WalFrame } \\
\text { (Model 2) }\end{array}$ & 6,394 & $2 l$ \\
\hline $\begin{array}{c}\text { Open First- } \\
\text { Story Frame } \\
\text { (Model 3) }\end{array}$ & 0,899 & 12,670 \\
\hline
\end{tabular}

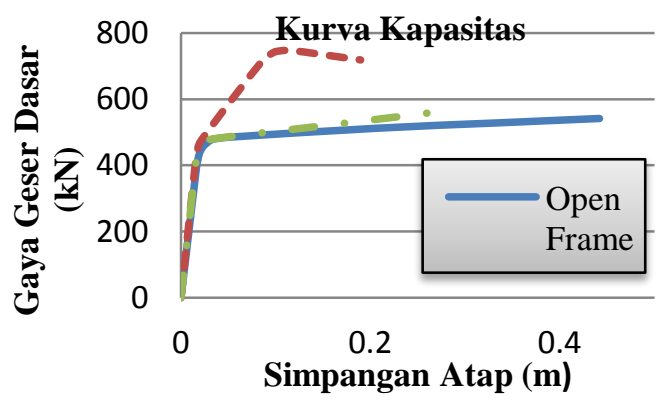

Gambar 3. Perbandingan kurva kapasitas

Dari hasil yang disajikan pada Tabel $1-2$ dan Gambar 3, dapat dilihat bahwa pada saat mencapai performance point kapasitas maksimal dari model struktur open frame berada di bawah kapasitas maksimal model struktur yang lain. Antara model 1 dengan model 2 dan 3 terdapat perbedaan gaya geser dasar berturut-turut sebesar 6,394\% dan 0,899\% Berdasarkan hasil yang diperoleh, keberadaan dinding bata yang dimodelkan sebagai diagonal tekan ekivalen akan menambah kapasitas struktur. Struktur dengan strut mampu menerima gaya geser dasar lebih baik daripada sturuktur open frame.

Di sisi lain jika ditinjau dari daktilitas, nilai daktilitas yang terbesar adalah model open frame (model 1), kemudian diikuti oleh open first-story frame (model 3) dan fully infilled wall (model 2). Dari analisis ini dapat ditarik 


\section{Mizanuddin Sitompul}

kesimpulan bahwa keberadaan dinding bata bisa mengakibatkan menurunnya daktilitas dari struktur, hasil studi menunjukkan terjadi penurunan sebesar $24,3 \%$. Dinding bata bisa menyebabkan struktur menjadi lebih kaku.

Pada saat mencapai performance point, nilai target perpindahan (displacement) yang dihasilkan oleh struktur open frame lebih besar dari model yang lain walaupun perbedaan nilainya kecil. Hal ini menunjukkan bahwa struktur open frame dapat berdeformasi lebih baik daripada struktur dengan strut.

Hasil analisis pushover masing-masing model dapat dilihat pada Tabel $3-4$.

Tabel 3 : Tabel pushover open frame (model 1)

\begin{tabular}{|c|c|c|c|c|c|c|c|c|c|c|}
\hline Step & $\begin{array}{l}\text { Displace } \\
\text { ment (m) }\end{array}$ & $\begin{array}{c}\text { Base } \\
\text { Force } \\
(\mathrm{kN})\end{array}$ & A-B & B-IO & IO-LS & LS-CP & CP-C & C-D & D-E & Total \\
\hline 0 & 0 & 0 & 84 & 0 & 0 & 0 & 0 & 0 & 0 & 84 \\
\hline 1 & 0,016474 & 396.632 & 83 & 1 & 0 & 0 & 0 & 0 & 0 & 84 \\
\hline 2 & 0,016633 & 400.245 & 80 & 4 & 0 & 0 & 0 & 0 & 0 & 84 \\
\hline 3 & 0,018782 & 429.085 & 76 & 8 & 0 & 0 & 0 & 0 & 0 & 84 \\
\hline 4 & 0,020735 & 444.376 & 73 & 11 & 0 & 0 & 0 & 0 & 0 & 84 \\
\hline 5 & 0,023169 & 455.498 & 68 & 16 & 0 & 0 & 0 & 0 & 0 & 84 \\
\hline 6 & 0,027217 & 466.864 & 65 & 19 & 0 & 0 & 0 & 0 & 0 & 84 \\
\hline 7 & 0,034401 & 479.050 & 60 & 24 & 0 & 0 & 0 & 0 & 0 & 84 \\
\hline 8 & 0,053 & 485.130 & 54 & 22 & 8 & 0 & 0 & 0 & 0 & 84 \\
\hline 9 & 0,207046 & 511.800 & 50 & 16 & 14 & 4 & 0 & 0 & 0 & 84 \\
\hline 10 & 0,331158 & 527.536 & 42 & 14 & 24 & 0 & 4 & 0 & 0 & 84 \\
\hline 11 & 0,441767 & 541.149 & 41 & 15 & 18 & 6 & 0 & 4 & 0 & 84 \\
\hline
\end{tabular}

Dari Tabel 3, Struktur open frame memiliki daktilitas displacement sebesar 11,89. Analisis berhenti pada step 11 dan diperoleh performance point, gaya geser dasar $=472,040 \mathrm{kN}$ dan target perpindahan $0,030 \mathrm{~m}$. Dengan target perpindahan $\delta_{t}=0,030 \mathrm{~m}$, terlihat bahwa pada step kinerja yang diperlihatkan struktur tidak ada yang melewati batas LS (Life Safety) sehingga kinerja struktur open frame secara keseluruhan baik

Tabel 4 : Tabel pushover fully infilled wall frame (model 2)

\begin{tabular}{|c|c|c|c|c|c|c|c|c|c|c|}
\hline Step & $\begin{array}{c}\text { Displa } \\
\text { cement } \\
(\mathbf{m})\end{array}$ & $\begin{array}{c}\text { Base } \\
\text { Force } \\
(\mathbf{k N})\end{array}$ & A-B & B-IO & IO-LS & LS-CP & CP-C & C-D & D-E & Total \\
\hline $\mathbf{0}$ & 0 & 0 & 120 & 0 & 0 & 0 & 0 & 0 & 0 & 120 \\
\hline $\mathbf{1}$ & 0,01476 & 395.314 & 119 & 1 & 0 & 0 & 0 & 0 & 0 & 120 \\
\hline $\mathbf{2}$ & 0,017182 & 436.477 & 112 & 8 & 0 & 0 & 0 & 0 & 0 & 120 \\
\hline $\mathbf{3}$ & 0,020908 & 473.734 & 104 & 16 & 0 & 0 & 0 & 0 & 0 & 120 \\
\hline $\mathbf{4}$ & 0,085749 & 715.437 & 45 & 47 & 18 & $\mathbf{8}$ & 0 & 0 & 0 & 120 \\
\hline $\mathbf{5}$ & 0,098754 & 742.374 & 45 & 44 & 21 & 6 & 0 & 0 & 0 & 120 \\
\hline $\mathbf{6}$ & 0,099694 & 743.434 & 45 & 44 & 21 & 5 & 0 & 0 & 0 & 120 \\
\hline $\mathbf{7}$ & 0,116322 & 746.757 & 44 & 41 & 23 & 6 & 0 & 0 & 0 & 120 \\
\hline $\mathbf{8}$ & 0,189669 & 718.217 & 44 & 39 & 25 & 6 & 0 & 0 & 0 & 120 \\
\hline
\end{tabular}

Dari Tabel 4, Struktur fully infilled wall frame memiliki daktilitas displacement sebesar 9. Analisis berhenti pada step 8 dan diperoleh performance point, gaya geser dasar $=502,223 \mathrm{kN}$ dan target perpindahan $0,029 \mathrm{~m}$. Dengan target perpindahan $\delta_{t}=0,029 \mathrm{~m}$, terlihat bahwa pada step kinerja yang diperlihatkan struktur ada yang melewati batas LS tetapi tidak ada yang melampaui batas CP (Collapse Prevention) sehingga kinerja struktur fully infilled wall frame tidak baik.
Tabel 5 : Tabel pushover open first-story (model 3)

\begin{tabular}{|c|c|c|c|c|c|c|c|c|c|c|}
\hline Step & $\begin{array}{c}\text { Displa } \\
\text { cement } \\
\text { (m) }\end{array}$ & $\begin{array}{c}\text { Base } \\
\text { Force } \\
\text { (kN) }\end{array}$ & A-B & B-IO & IO-LS & LS-CP & CP-C & C-D & D-E & Total \\
\hline 0 & 0 & 0 & 114 & 0 & 0 & 0 & 0 & 0 & 0 & 114 \\
\hline 1 & 0,015075 & 395.975 & 113 & 1 & 0 & 0 & 0 & 0 & 0 & 114 \\
\hline 2 & 0,015229 & 399.770 & 110 & 4 & 0 & 0 & 0 & 0 & 0 & 114 \\
\hline 3 & 0,017305 & 429.574 & 106 & 8 & 0 & 0 & 0 & 0 & 0 & 114 \\
\hline 4 & 0,019401 & 447.259 & 101 & 13 & 0 & 0 & 0 & 0 & 0 & 114 \\
\hline 5 & 0,026043 & 475.524 & 94 & 20 & 0 & 0 & 0 & 0 & 0 & 114 \\
\hline 6 & 0,146257 & 517.917 & 87 & 19 & 4 & 4 & 0 & 0 & 0 & 114 \\
\hline 7 & 0,249241 & 553.274 & 74 & 28 & 4 & 0 & 8 & 0 & 0 & 114 \\
\hline 8 & 0,27223 & 561.094 & 72 & 30 & 4 & 0 & 4 & 4 & 0 & 114 \\
\hline 9 & 0,286359 & 537.034 & 72 & 30 & 4 & 0 & 2 & 6 & 0 & 114 \\
\hline 10 & 0,392486 & 150.010 & 72 & 30 & 4 & 0 & 0 & 4 & 4 & 114 \\
\hline 11 & 0,410635 & 115.822 & 72 & 30 & 4 & 0 & 0 & 2 & 6 & 114 \\
\hline 12 & 0,432965 & 94.837 & 72 & 30 & 4 & 0 & 0 & 0 & 8 & 114 \\
\hline 13 & 0,495209 & 94.839 & 72 & 30 & 4 & 0 & 0 & 0 & 4 & 114 \\
\hline 14 & 0,50722 & 72.122 & 72 & 30 & 4 & 0 & 0 & 0 & 2 & 114 \\
\hline 15 & 0,522053 & 16.622 & 72 & 30 & 4 & 0 & 0 & 0 & 0 & 114 \\
\hline 16 & 0,523288 & 14.294 & 72 & 30 & 4 & 0 & 0 & 0 & 0 & 114 \\
\hline 17 & 0,538482 & 0,012 & 71 & 30 & 4 & 0 & 0 & 0 & 0 & 114 \\
\hline
\end{tabular}

Dari Tabel 5, Struktur open first-story frame memiliki daktilitas displacement sebesar 10,38. Analisis berhenti pada step 17 dan diperoleh performance point, gaya geser dasar $=476,285 \mathrm{kN}$ dan target perpindahan $0,028 \mathrm{~m}$. Dengan target perpindahan $\delta_{t}=0,028 \mathrm{~m}$, terlihat bahwa pada step kinerja yang diperlihatkan struktur ada yang melewati batas LS tetapi tidak ada yang melampaui batas $\mathrm{CP}$ sehingga kinerja struktur fully infilled wall frame tidak baik.

Dari sendi plastis yang terjadi, sendi plastis akan muncul terlebih dahulu pada balok atau kaki kolom kemudian terjadi pada kolom. Dengan adanya strut pada model 2 dan 3 mengakibatkan sebagian gaya yang bekerja ke balok akan diterima juga oleh strut.

Di bawah pengaruh beban gempa kuat, secara keseluruhan hanya struktur open frame saja yang memiliki kinerja yang baik (karena saat performance point berada pada daerah BIO). Struktur fully infilled wall dan open firststory pada saat mencapai performance point berada pada daerah LS-CP yang menunjukkan bahwa kinerja struktur kurang baik. Khusus struktur open first-story terjadi mekanisme keruntuhan soft story yang ditandai dengan terbentuknya sendi plastis pada kolom lantai pertama. Sudah kita ketahui bahwa kolom merupakan penyangga berdirinya suatu bangunan, keruntuhan soft story yang terjadi akibat hancurnya kolom pada salah satu lantai akan mengakibatkan kegagalan struktur

\section{Simpulan}

Dari hasil analisis dapat ditarik Simpulan sebagai berikut:

1) Hasil studi menunjukkan bahwa kontribusi dinding pengisi yang terbuat dari dinding bata sangat mempengaruhi kekakuan lateral struktur. Adanya dinding pengisi yang kaku di sebuah level tingkat dan pada level tingkat lain tidak ada (dalam hal ini diwakilkan oleh model 3) 
dapat menyebabkan efek tingkat lemah (soft story). Mekanisme keruntuhan soft story ini dapat menyebabkan kegagalan struktur.

2) Keberadaan dinding pengisi bata ternyata bisa mengurangi daktilitas struktur, dari studi ini diperoleh pengurangan sebesar $24,3 \%$.

\section{Daftar Pustaka}

Aryanto, A. (2008) Kinerja Portal Beton Bertulang dengan Dinding Pengisi Bata Ringan terhadap Beban Gempa. Tesis Magister, Institut Teknologi Bandung, Bandung.

Dewobroto, W. (2005) Analisa Inelastis PortalDinding Pengisi dengan Equivalent Diagonal Strut. Jurnal Teknik Sipil, Vol. 12.

Haselton, C. B., Liel, A. B., Deierlein, G. G., Dean, B. S., Chou, J. H. (2011) Seismic collapse safety of reinforced concrete building. I: assessment of ductile moment frames. Journal of Structural Engineering, ASCE, 137(4), 481-491.

Rozman, M., dan Fajfar, P. (2009) Seismic response of a $\mathrm{RC}$ frame building designed according to old and modern practices. Bulletin of Earthquake Engineering, 7(3), 779799.

Saneinejad, A., dan Hobbs, B. (1995) Inelastic design of infilled frames. Journal of Structural Engineering, ASCE, 121(4), 634650.

Sitompul, M. (2015) Studi Parametrik Kinerja Dinding Pengisi Bata Merah pada Struktur Beton Bertulang Akibat Beban Gempa. Tesis Magister, Universitas Sumatera Utara, Medan.

Zareian, F, Krawinkler, H. (2007) Assessment of probability of collapse and design for collapse safety. Earthquake Engineering and Structural Dynamics, 36, 1901-1914. 